\title{
Stem cells in human neurodegenerative disorders — time for clinical translation?
}

\author{
Olle Lindvall1,2 and Zaal Kokaia ${ }^{2,3}$
}

\begin{abstract}
${ }^{1}$ Laboratory of Neurogenesis and Cell Therapy, Wallenberg Neuroscience Center, University Hospital, Lund, Sweden. 2Lund Stem Cell Center, Lund, Sweden. ${ }^{3}$ Laboratory of Neural Stem Cell Biology and Therapy, University Hospital, Lund, Sweden.
\end{abstract}

\begin{abstract}
Stem cell-based approaches have received much hype as potential treatments for neurodegenerative disorders. Indeed, transplantation of stem cells or their derivatives in animal models of neurodegenerative diseases can improve function by replacing the lost neurons and glial cells and by mediating remyelination, trophic actions, and modulation of inflammation. Endogenous neural stem cells are also potential therapeutic targets because they produce neurons and glial cells in response to injury and could be affected by the degenerative process. As we discuss here, however, significant hurdles remain before these findings can be responsibly translated to novel therapies. In particular, we need to better understand the mechanisms of action of stem cells after transplantation and learn how to control stem cell proliferation, survival, migration, and differentiation in the pathological environment.
\end{abstract}

\section{Introduction}

Neurodegenerative disease is a term used for a wide range of acute and chronic conditions in which neurons and glial cells in the brain and spinal cord are lost. In acute cases, for example, in response to ischemic stroke or spinal cord injury, different types of neurons and glial cells die within a restricted brain area over a short time period. In chronic cases, there is either a selective loss of a specific cell population, such as dopamine (DA) neurons in Parkinson disease (PD) and motor neurons in amyotrophic lateral sclerosis (ALS), or a widespread degeneration of many types of neuron, such as occurs in Alzheimer disease (AD), over a period of several years. Stem cell-based approaches could be used therapeutically to restore function in neurodegenerative disease. For example, it might be possible to replace lost neurons or glial cells by transplantation of stem cell-derived cells that have been predifferentiated in vitro to various stages of maturation, e.g., into neuroblasts (i.e., immature neurons). Cell replacement might also be achieved by inducing endogenous stem cells in the adult CNS to form new neurons and glial cells. Besides these mechanisms, grafted stem cells and their derivatives could induce functional improvement by releasing therapeutic molecules that are neuroprotective or modulate inflammation.

Although some scientifically founded clinical trials using stem cells to treat neurodegenerative disorders have already been performed or initiated (e.g., for the rare, fatal, autosomal recessive neurodegenerative disorder Batten disease [http:/www.clinicaltrials.gov/ct2/show/NCT00337636?term-batten\&rank=4]), no stem cell-based therapy has yet been proven beneficial for any such condition. Despite this fact, unproven treatments for several neurodegenerative diseases are offered at "clinics" around the world without rationale and with poor scientific and clinical basis. The vast majority of these sites overpromise the results and gravely underestimate the potential risks (1).

For the successful development of stem cell-based therapies for neurodegenerative diseases, clinical roadmaps need to be defined. Specifically, the major milestones in basic and clinical research that need to be reached before such therapies can be tested in

Conflict of interest: The authors have declared that no conflict of interest exists. Citation for this article: J. Clin. Invest. 120:29-40 (2010). doi:10.1172/JCI40543. patients need to be established, and all the associated ethical, regulatory, societal, and economical issues need to be addressed. Here, we discuss some general issues relating to the clinical translation of stem cells. We also describe how far stem cell-based approaches for treating some acute and chronic neurodegenerative disorders have advanced and define the critical milestones that remain if these are to reach the clinic.

\section{General issues in developing stem cell-based therapies for neurodegenerative diseases}

If current knowledge of stem cells is to be translated into a treatment for neurodegenerative disease, four main issues are important to consider. First, it is necessary to define what is required for the stem cell-based approach to be clinically competitive and what risks to the patient are acceptable. Neurodegenerative diseases differ widely in the degree of disability that they cause and in the therapeutic options that are available. Patients with PD have a virtually normal life expectancy, several drugs are effective during the first years, and valuable symptomatic treatment can be given during the advanced stages of the disease. In contrast, there is no effective treatment for ALS, a rapidly progressing, fatal disorder. These distinct disease characteristics must come into play when the clinical application of an experimental and potentially risky stem cell-based treatment is being considered. If an efficacious therapy already exists, as in PD, the risk of an adverse effect, based on findings in preclinical animal models, must be low and the stem cell-based approach must offer a substantial advantage (e.g., better functional outcome, single procedure versus lifelong drug therapy with associated side effects, and/or cost-effectiveness). If efficacious therapy is lacking, the severity of a disease such as ALS might justify the potential risks of a stem cellbased experimental intervention in patients. With regard to assessing the safety of stem cell-based approaches, it must be emphasized that stem cells and their derivatives represent in most cases entirely novel products. Their proliferation and differentiation are difficult to control. Animal models may not fully predict their toxicity, occurrence of immune and other biologic responses, and risk for tumor formation after implantation in patients.

Second, disease pathology has to determine which cells should be generated from stem cells; for cell replacement therapy, different cells will be needed for different diseases. Substantial improve- 


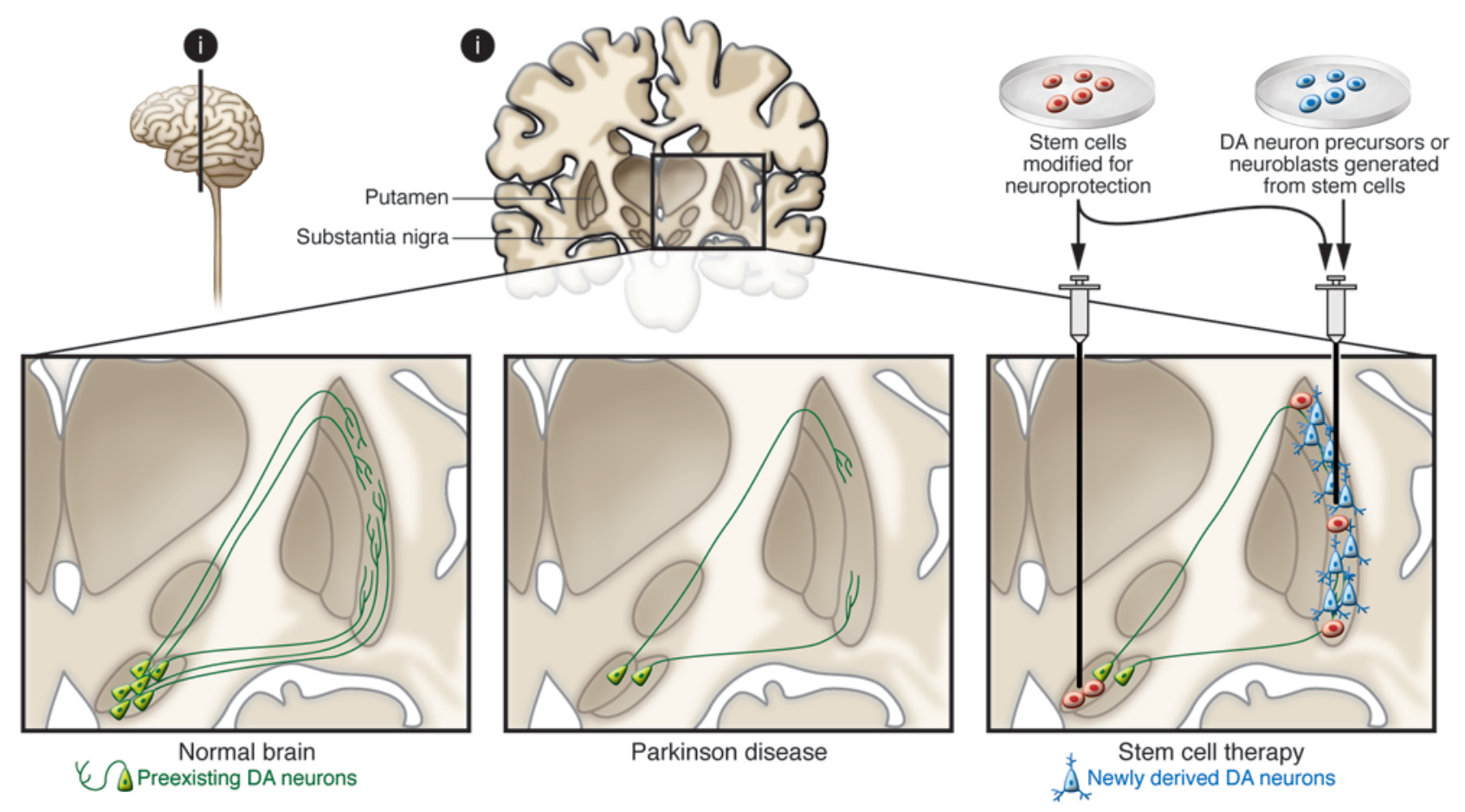

Figure 1

Stem cell-based therapies for PD. PD leads to the progressive death of DA neurons in the substantia nigra and decreased DA innervation of the striatum, primarily the putamen. Stem cell-based approaches could be used to provide therapeutic benefits in two ways: first, by implanting stem cells modified to release growth factors, which would protect existing neurons and/or neurons derived from other stem cell treatments; and second, by transplanting stem cell-derived DA neuron precursors/neuroblasts into the putamen, where they would generate new neurons to ameliorate disease-induced motor impairments.

ment in PD and ALS would require cells with the properties of DA and motor neurons, respectively, whereas cell replacement in stroke and $\mathrm{AD}$ would need several cell types to be effective. Disease pathology may also affect the cells derived from the transplanted cells, as has been observed in intrastriatal grafts of embryonic mesencephalic tissue more than a decade after they were implanted in PD patients $(2,3)$. This may be particularly relevant when patientspecific cells are produced by therapeutic cloning (i.e., from ES cells generated by removing the nucleus from an egg and replacing it with the nucleus from a somatic cell from the transplant recipient) or by induced pluripotent stem (iPS) cell technology, leading to increased susceptibility to the disease process. A major advantage, however, especially with the iPS cell approach, is the potential to develop human cell-based disease models of sporadic and genetically complex diseases such as PD (4).

Third, prior to clinical application, it must be demonstrated in animal models that the stem cell-based approach induces substantial improvement of functional deficits that resemble the debilitating symptoms in patients. However, the behavior of stem cells, or cells predifferentiated from them in vitro, after transplantation in animal models may only partly reflect how these cells will behave in patients. The animal model may not mimic all aspects of the pathology of the human condition, leading to lack of efficacy of the stem cell-derived product in the clinical trial.

Last, it is important to determine the biological mechanism underlying the observed effects of a stem cell-based treatment in an animal model. For optimal recovery from a neurodegenerative disease, neuronal replacement and at least partial reconstruction of neuronal circuitry, such as restoration of striatal DA transmission in PD, should probably be the aim. However, stem cells can lead to functional improvements that could be clinically valuable through mechanisms other than cell replacement, for example, immunomodulation. Indeed, systemically administered mouse neural stem cells (NSCs) have been shown to migrate to demyelinating lesions in mouse brain and give rise to neuroprotection by suppressing proinflammatory mechanisms (5).

\section{Stem cell-based therapies for PD}

Degeneration of nigrostriatal DA neurons is the main pathology in PD (Figure 1), although other dopaminergic and non-dopaminergic systems are also affected. Characteristic symptoms are rigidity, hypokinesia, tremor, and postural instability. Although motor symptoms can be treated relatively well with L-3,4-dihydroxyphenylalanine (L-DOPA), DA agonists, enzyme inhibitors, and deep brain stimulation, effective therapies for nonmotor symptoms, such as dementia, are lacking, and disease progression cannot be counteracted. Clinical trials with intrastriatal transplantation of human embryonic mesencephalic tissue, which is rich in postmitotic DA neuroblasts, have provided proof of principle that neuronal replacement can work in PD patients (Figure 1) (6). The DA neurons that form from the transplanted tissue reinnervate the denervated striatum and become functionally integrated, restoring striatal DA release and giving rise to clear symptomatic relief in some patients (see, e.g., ref. 6). Although a small fraction of graft-derived DA neurons contain Lewy bodies (the hallmark of PD) 11-16 years after transplantation $(2,3)$, cell replacement remains a viable therapeu- 
tic option for PD. The progression of pathology in graft-derived neurons is slow, and they are still functional after a decade, with patients showing long-term clinical benefit (7). However, there is a strong need for other sources of DA neurons, because availability of human embryonic mesencephalic tissue is limited and variability of functional outcome after transplantation is high. Some patients have improved to the extent that L-DOPA could be withdrawn for several years (7), whereas others have exhibited modest, if any, clinical benefit $(8,9)$. Poor standardization of the transplanted cell material contributes to the high variability, but this problem and the lack of human embryonic mesencephalic tissue for transplantation could be solved if large numbers of standardized DA neuroblasts were generated from stem cells.

After transplantation of stem cell-derived DA neuron precursors or neuroblasts (Figure 1) and subsequent maturation, the resultant cells must exhibit the properties of substantia nigra neurons in order to induce substantial benefit in PD $(10,11)$. DA neuroblasts for preclinical transplantation have been generated in vitro from stem cells from several different sources and species, including humans. For example, they have been derived from ES cells (12-19), therapeutically cloned ES cells (20), NSCs and progenitors of embryonic ventral mesencephalon (21-24), adult NSCs from the subventricular zone (SVZ) (25), bone marrow stem cells (26), and fibroblast-derived iPS cells (27). Overexpressing in the stem cells transcription factors that determine mesencephalic DA-neuron specification or maturation during normal development can increase the yield of DA neuroblasts with the correct phenotype $(15,21,28-30)$. Mouse ES cell-derived DA neuroblasts can also be enriched to greater than $90 \%$ purity by FACS; after transplantation in a rat model of PD (31), these sorted cells were functional, but fewer survived as compared with non-sorted cells.

Human stem cell-derived DA neuron precursors/neuroblasts, which will be required for patient application, can survive in animal models of PD and, after maturation, exert functional effects $(13,17$, $23,26)$. However, some properties that are fundamental for successful clinical translation have not yet been demonstrated for human stem cell-derived DA neurons. For example, it has not been shown that they can substantially reinnervate striatum, restore DA release in vivo, and markedly improve deficits resembling the symptoms experienced by patients with PD. Experimental work establishing these properties remains to be performed before a human stem cell-derived DA neuron precursor or neuroblast can be selected as a candidate cell for patient application. A major concern when transplanting ES cell-derived DA neuroblasts is the risk for tumor formation, which has been observed in animal models (17). As patients with PD have normal life expectancy, even a minor risk of tumor formation is unacceptable in this clinical context. Engineering stem cells to express suicide genes that can be switched on when desired (after therapeutic progeny have been generated) and use of cell sorting (30) to eliminate tumor-forming cells may improve safety.

The use of patient-specific DA neuroblasts made from iPS cells $(4,27,32)$ for transplantation would eliminate ethical concerns associated with ES cells and their progeny and, as with DA neurons derived through therapeutic cloning (20), would avoid immune reactions. However, before application can be considered in patients, the tumor risk, which is similar to that with ES cell-derived neuroblasts, has to be eliminated. The growth and functionality of the DA neurons should also be determined. The patient may exhibit a gene profile that would make the grafted, patient-specific DA cells particularly susceptible to PD pathology.
In order to be clinically competitive, a stem cell-based DA cell replacement therapy has to induce substantial (at least 50\%-70\%) amelioration of motor symptoms without significant side effects. This could be achieved if patients are carefully selected and the dose and site of implantation of the DA cells are based on preoperative imaging. Patients with DA denervations restricted to the caudateputamen (a region of the brain involved in regulating movement) need grafts only in these areas to experience major benefits (33). In contrast, $\mathrm{PD}$ patients with more widespread denervations that include areas of the ventral striatum and cerebral cortex will also require grafts in these areas. Troublesome off-medication dyskinesias have been observed in a group of patients receiving embryonic mesencephalic grafts $(8,9,34)$. Strategies to prevent their occurrence following cell replacement therapy must be developed; minimizing the number of serotonergic neuroblasts in the transplant material, as suggested by animal studies (35), and distributing the DA neuroblasts evenly over the putamen might both be helpful in this regard. Importantly, PD is a multisystem disorder, and symptoms that are caused by pathology in nondopaminergic systems will not be improved by intrastriatal DA grafts (36). Finally, for long-term functional restoration in PD patients, DA cell replacement has to be combined with a neuroprotective therapy to hinder disease progression (37). One possible strategy could be concomitant transplantation of stem cells genetically modified to secrete a trophic factor such as glial cell line-derived neurotrophic factor (GDNF) (38) into the striatum and substantia nigra (Figure 1).

\section{Stem cell-based therapies for ALS}

In ALS, dysfunction and degeneration of motor neurons in the spinal cord, cerebral cortex, and brainstem cause rapidly progressing muscle weakness and death within a few years (Figure 2). There is no effective treatment. Motor neurons have been generated in vitro from stem cells from various sources, including mouse and human ES cells (39-43), NSCs derived from fetal rat spinal cord (44) and human forebrain (45), and human iPS cells $(46,47)$. Stem cellderived motor neuron precursors and neuroblasts establish functional synapses with muscle fibers in vitro $(48,49)$, extend axons to ventral roots after transplantation into the spinal cord of adult rats with motor neuron injury $(44,48,50)$, form neuromuscular junctions with host muscle, and give rise to partial recovery from paralysis (50). After transplantation into transected tibial nerves of adult mice and maturation, mouse ES cell-derived motor neurons exhibit normal motor units and attenuate muscle atrophy (51).

If cell replacement therapy is to be a clinical success in ALS (Figure 2), several experimental hurdles must be overcome. First, it must be shown that the cells can be delivered at multiple sites along the spinal cord. Second, it must be determined whether the stem cell-derived motor neurons integrate into existing spinal cord neural circuitries, receive appropriate regulatory input, and are able to extend their axons long distances to reinnervate muscles in humans. Third, it must be established that the differentiation of the spinal motor neurons can be directed to the correct cervical (43), thoracic (41), or lumbar phenotype and that the final cell population projects to axial (52) or limb muscles. Fourth, it must be shown that central motor neurons such as corticospinal neurons, which degenerate in ALS (Figure 2), also can be replaced for effective, life-saving restoration of function. Developing approaches to harness factors involved in cortico-spinal neuron specification $(53)$ and axonal outgrowth $(54,55)$ will be important to direct transplanted stem cell-derived neurons to the 

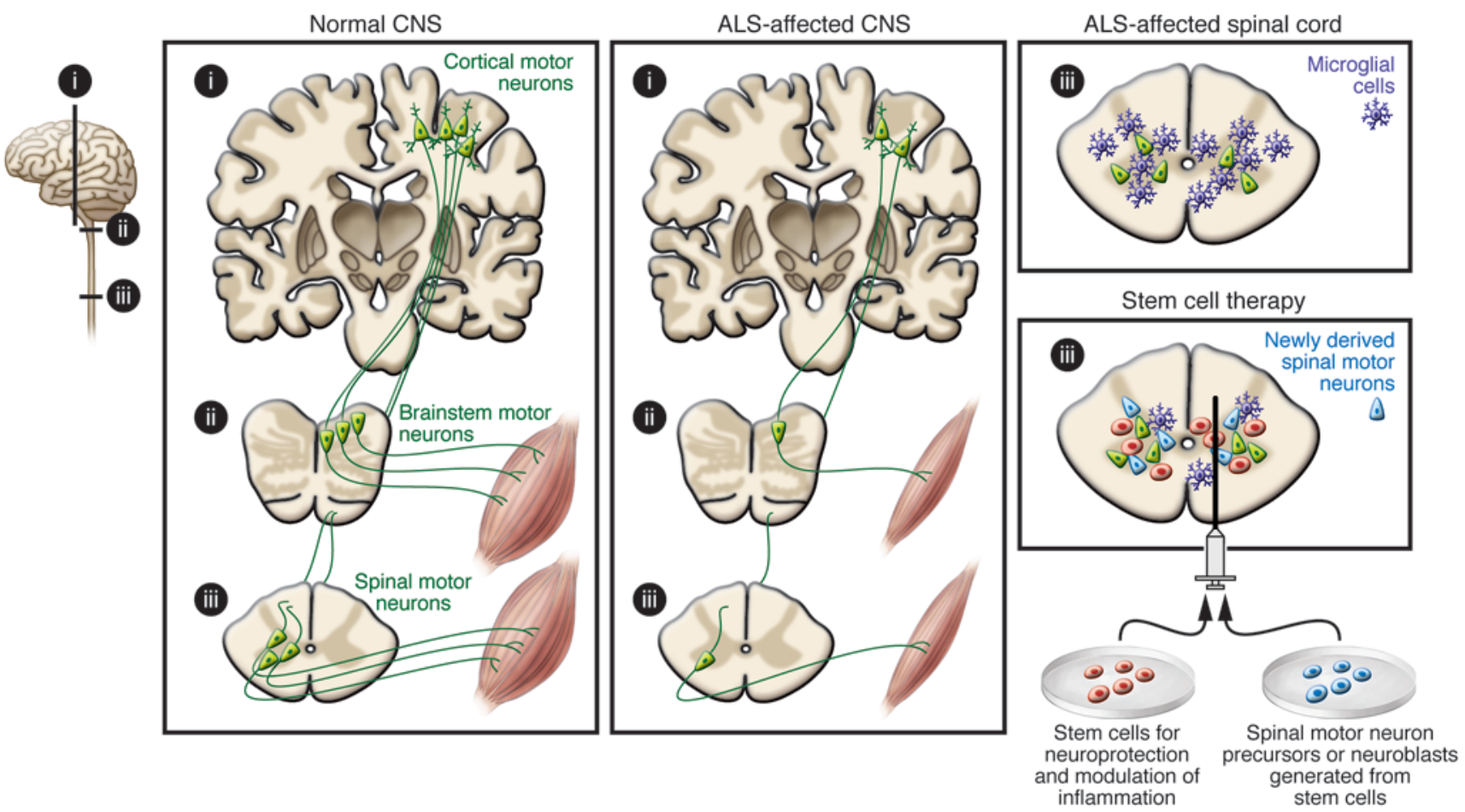

Figure 2

Stem cell-based therapies for ALS. ALS leads to degeneration of motor neurons in the cerebral cortex, brainstem, and spinal cord. Stem cell-based therapy could be used to induce neuroprotection or dampen detrimental inflammation by implanting stem cells releasing growth factors. Alternatively, stem cell-derived spinal motor neuron precursors/neuroblasts could be transplanted into damaged areas to replace damaged or dead neurons.

correct phenotype. Last, it must be determined whether the environment in the spinal cord of a patient with ALS, which is hostile to motor neurons, can be altered. Importantly, glial cells carrying an ALS-causing genetic mutation impair the survival of human ES cell-derived motor neurons in culture $(56,57)$. Modification of the patient's microglial cells or astrocytes may therefore be necessary for long-term survival of transplanted motor neurons. Evidence to suggest that this approach might work has been provided by the observation that transplantation of normal astrocyte precursors into the spinal cord attenuated motor neuron loss and functional decline in a mouse model of ALS (58). With continuous scientific progress stem cell-based therapy for replacing motor neurons is promising, but there is much work ahead before it can move to the clinic as a treatment for ALS.

Transplantation of stem cells to counteract motor neuron loss by releasing neurotrophic molecules or modifying the inflammatory environment, which probably plays a major role in disease progression (59), is a more realistic near-term clinical goal for ALS (Figure 2). Indeed, the US company NeuralStem has received FDA approval for a clinical trial in which 12 patients with ALS will be treated by injection of human fetal-derived NSCs into the lumbar region of the spinal cord, where it is hoped they will exert a neuroprotective effect. Several lines of preclinical experimental data have provided the rationale for this approach, some of which are discussed here. First, derivatives of human embryonic germ cells (pluripotent cells derived from primordial germ cells in the gonadal ridge) delivered into the cerebrospinal fluid of rats with motor neuron injury have been found to migrate into the parenchyma and induce motor recovery through neuroprotection as a result of growth factor production (60). Second, intraspinal injection of mouse NSCs in a mouse model of ALS has been shown to give rise to neuron formation, delay disease onset and progression, and protect motor neurons, probably through VEGF- and IGF-1-dependent mechanisms (61). Third, similar effects have been observed after intrathecal implantation of human VEGF-overexpressing NSCs in a mouse model of ALS (62). Fourth, human fetal NSCs transplanted into the spinal cord in a rat model of ALS have been found to protect motor neurons and delay disease onset (63), probably as a result of their neuronal progeny (i.e., GABAergic interneurons synapsing on host motor neurons) releasing GDNF and brain-derived neurotrophic factor (BDNF), dampening excitotoxicity, or both (64). Fifth, cortical, GDNF-secreting human NSCs have been shown to survive implantation into the spinal cord in a rat model of ALS, migrate into degenerating areas, and increase motor neuron survival, although they did not improve limb function due to a lack of continued innervation of muscle end plates $(65,66)$. However, when human mesenchymal stem cells (MSCs) engineered to secrete GDNF were transplanted into the muscles of rats with an ALS-like disease, motor function improved and disease progression was delayed (67). Compared with direct gene transfer, an advantage of cell-based gene delivery is that production of the trophic factor continues even if the disease process destroys the endogenous cells.

HSC transplantation or delivery of MSCs in order to alter the inflammatory environment has already reached the clinic (Figure 2). Although allogeneic HSCs transplanted intravenously in six ALS patients did not provide any clinical benefit, donor-derived cells were found to localize to the sites of pathology, which may render them particularly suitable for delivering therapeutic mol- 

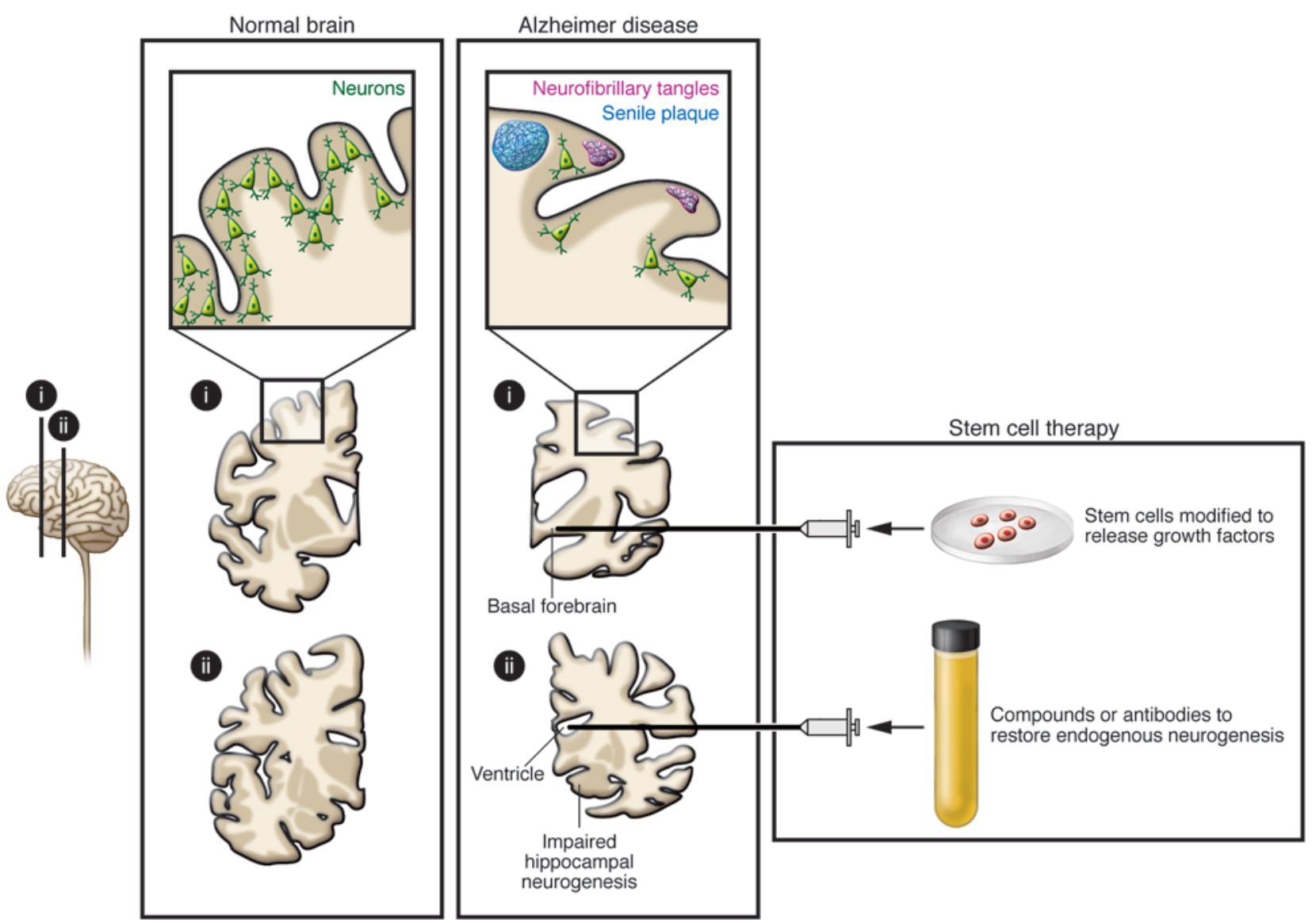

Figure 3

Stem cell-based therapies for AD. AD leads to neuronal loss in the basal forebrain cholinergic system, amygdala, hippocampus, and cortical areas of the brain; formation of neurofibrillary tangles; and $\beta$-amyloid protein accumulation in senile plaques. Stem cell-based therapy could be used to prevent progression of the disease by transplanting stem cells modified to release growth factors. Alternatively, compounds and/or antibodies could be infused to restore impaired hippocampal neurogenesis.

ecules (68). In another study, nine patients received intraspinal injections of autologous MSCs (69), an approach taken because experiments in a mouse model of ALS indicated that lumbar injection of human MSCs dampened inflammation and reduced motor neuron loss and functional impairment (70). In yet another study, HSC transplantation using cervical intraspinal injections was performed in 13 patients (71). These two open-label studies reported clinical benefit, but preclinical data on safety, dosage, long-term survival, differentiation, and functional efficacy were insufficient, and without a control group, the clinical evidence of improvement is weak. In our view, more preclinical studies are needed prior to further patient applications (72).

\section{Stem cell-based therapies for AD}

Patients with $\mathrm{AD}$ exhibit memory impairment, cognitive decline, and dementia due to widespread and progressive pathological changes (Figure 3). Neuronal and synaptic loss, neurofibrillary tangles, and deposits of $\beta$-amyloid protein in senile plaques involve the basal forebrain cholinergic system, amygdala, hippocampus, and cortical areas. The situation for neuronal replacement aiming at functional restoration in $\mathrm{AD}$ is extremely complex because the stem cells would have to be predifferentiated in vitro to many different types of neuroblasts for subsequent implantation in a large number of brain areas. Since acetylcholinesterase inhibitors, which enhance cholinergic function, induce some temporary improvement in $\mathrm{AD}$ patients, the cognitive decline could hypothetically be improved by transplantation of stem cell-derived basal forebrain cholinergic neurons. Experimental evidence indicates that it should be possible to generate such cells from stem cells (73). However, to give long-lasting symptomatic benefit, a cholinergic cell replacement approach would require intact target cells, host neurons that the new cholinergic neurons can act on, and they are probably damaged in AD. Stem cell-based cell replacement strategies are very far from clinical application in $\mathrm{AD}$.

The disease symptoms in AD could partly be due to impaired formation of new hippocampal neurons from endogenous NSCs in the subgranular zone of the dentate gyrus, which is believed to contribute to mood regulation, learning, and memory (Figure 3) (74). Mouse models of AD have provided equivocal data, with studies demonstrating both increased and decreased hippocampal neurogenesis (75), one important factor being disease severity, with a compensatory increase in progenitor proliferation in the early stages and decreased proliferation and survival with advanced pathology $(76,77)$. Formation of immature hippocampal neurons has been reported to increase in senile AD patients (78), while in another study, neurogenesis was not 
Stem cell therapy

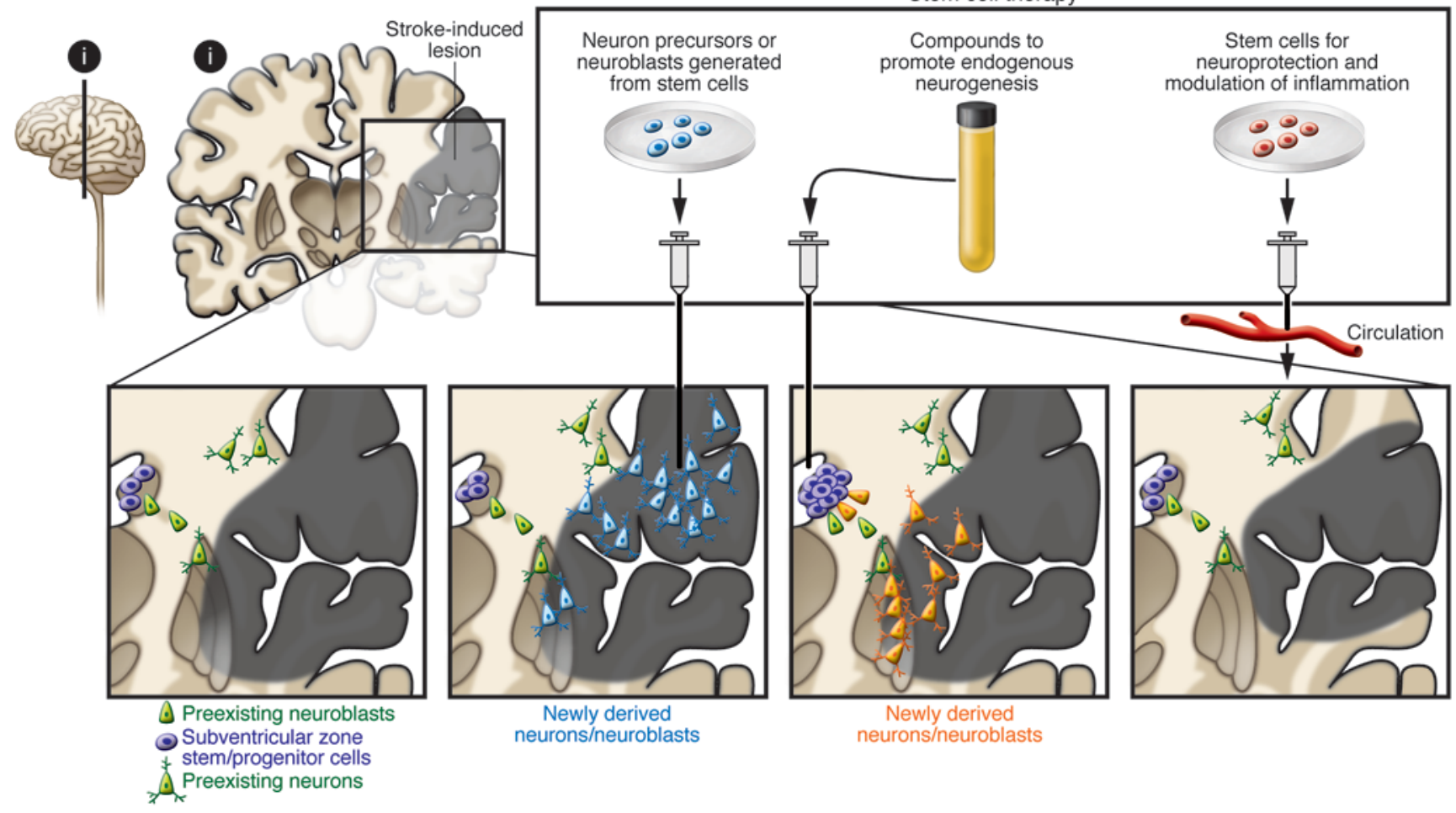

Figure 4

Stem cell-based therapies for stroke. Ischemic stroke leads to the death of multiple neuronal types and astrocytes, oligodendrocytes, and endothelial cells in the cortex and subcortical regions. Stem cell-based therapy could be used to restore damaged neural circuitry by transplanting stem cell-derived neuron precursors/neuroblasts. Also, compounds could be infused that would promote neurogenesis from endogenous SVZ stem/progenitor cells, or stem cells could be injected systemically for neuroprotection and modulation of inflammation.

altered in presenile cases (79). Later studies have indicated deficient maturation of new neurons in $\mathrm{AD}$ brains (80). As a result, approaches to enhance neurogenesis and/or maturation could be considered potential stem cell-based therapies for $\mathrm{AD}$. Clearance of brain $\beta$-amyloid has been proposed to be of value in halting disease progression in $\mathrm{AD}$. Active $\beta$-amyloid vaccination in young $\mathrm{AD}$ mice, using as antigen a sequence of the $\beta$-amyloid peptide, decreased $\beta$-amyloid burden and increased hippocampal neurogenesis (81). Moreover, passive $\beta$-amyloid immunotherapy with an antibody specific for aggregated $\beta$-amyloid restored neurogenesis and morphological maturation of new hippocampal neurons in aged transgenic mice with $\beta$-amyloid-related impairments of neurogenesis (77). Taken together, the findings indicate that $\mathrm{AD}$ disturbs hippocampal neurogenesis, which may contribute to the cognitive deficits experienced by patients, suggesting that normalization of the formation and maturation of new hippocampal neurons, for example, by active or passive $\beta$-amyloid immunotherapy, could have therapeutic potential (Figure 3).

Stem cell-based gene therapy could deliver factors modifying the course of $\mathrm{AD}$ (Figure 3 ) and may be advantageous because of the capacity of stem cells to migrate and reach large areas of the brain. Preclinical studies that provide a rationale for this approach include one demonstrating that basal forebrain grafts of fibroblasts producing nerve growth factor (NGF), which counteracts cholinergic neuronal death, stimulate cell function and improve memory in animal models of AD (see ref. 82). Indeed, basal forebrain grafts of NGF-secreting fibroblasts have proven to be of some benefit to patients with $\mathrm{AD}$ in an open-label trial (82), and basal forebrain implantation of encapsulated retinal pigment epithelial cells releasing NGF is currently being tested in six patients with AD by the Danish company NsGene. Stem cells could also be engineered to carry other genes, such as that encoding BDNF, which has substantial neuroprotective effects in $\mathrm{AD}$ models (83). Transplantation of fibroblasts producing the $\beta$-amyloid-degrading protease neprilysin have been shown to reduce plaque burden in $\mathrm{AD}$ mice (84), although this may not lead to reduction in the number of pathogenic $\beta$-amyloid oligomers or prevent cognitive deficits (85).

\section{Stem cell-based therapies for stroke}

Ischemic stroke, which is caused by occlusion of a cerebral artery, leads to focal tissue loss and the death of multiple neuron types, as well as oligodendrocytes, astrocytes, and endothelial cells (Figure 4). Neuronal plasticity and reorganization of neural circuitries contribute to spontaneous recovery to varying degrees, but most patients exhibit persistent motor, sensory, or cognitive impairments. Apart from acute thrombolysis, which can be used in only a minority of cases, there is no effective treatment to promote recovery.

Different stem cells and their derivatives of rodent and human origin can survive, differentiate into neurons, and restore function after transplantation in the stroke-damaged rodent brain (Figure 4) (see refs. 86, 87). Human ES cell-derived NSCs, grafted into the ischemic boundary zone in rats subjected to stroke, have been 
shown to migrate toward the lesion and improve forelimb performance (88). Electrophysiological recordings showed functional neuronal properties in the grafted cells and synaptic input from host neurons (89), as has been observed for mouse ES cell-derived precursors implanted in stroke-damaged rat brain (90). Transplanted human fetal NSCs have also given rise to neurons that migrate toward the ischemic lesion in rodents (91), while human NSCs isolated from embryonic striatum and cortex (92) have generated morphologically mature neurons after transplantation into stroke-damaged rat striatum (93). Taken together, these findings provide evidence that replacement of functional neurons using stem cell grafts is possible in the stroke-damaged brain and suggest that this mechanism contributes to the observed behavioral improvements (Figure 4).

Various types of stem cells, primarily NSCs and MSCs, have been shown to ameliorate post-stroke functional impairments in rodents by other mechanisms as well (Figure 4). Using stem cell-based approaches in this manner could become of clinical value, but it is important that the efficacy and risks of using stem cells are compared with those of other treatments aiming at the same therapeutic targets. For example, intravenous injection of human NSCs has been shown to induce improvements after hemorrhagic stroke in rats, probably through antiinflammatory actions (94). Overexpression of either VEGF or the antiapoptotic factor Akt1 in human NSCs promotes angiogenesis and increases neuronal survival, respectively, enhancing the functional improvements in stroke-damaged mice $(95,96)$. In addition, intravenously administered human MSCs have been found to reduce stroke-induced deficits in rats, most likely by inducing angiogenesis and improving cerebral blood flow (97). When these human MSCs were genetically modified to express angiopoietin or growth factors such as GDNF, neuroprotection and functional improvement were further enhanced (97-100). Finally, human ES cell-derived MSCs injected intravenously in rats have been shown to migrate to the infarct region, express neuronal and endothelial cell markers, provide neuroprotection, and improve recovery (101). Importantly, mouse NSCs delivered intravenously 3 days after stroke in mice have been shown to suppress inflammation and glial scar formation and give rise to delayed neuroprotection and improved functional recovery, starting 18 days after the insult (102). This last finding suggests an extended time window for neuroprotection using NSCs.

Initial clinical trials with delivery of stem cells in stroke have been completed (for details see, e.g., ref. 87). For example, an immortalized human teratocarcinoma cell line, implanted into ischemic/hemorrhagic infarcts affecting the basal ganglia and in some cases also the cerebral cortex (103-105), induced slight improvements in some patients. No substantial clinical improvements were detected after intravenous injection of autologous MSCs in patients with an ischemic lesion in the territory supplied by the middle cerebral artery (106). Several clinical studies using intravenous or intraarterial (into damaged territory) infusion of autologous bone marrow-derived stem cells in stroke patients are ongoing or planned (www.clinicaltrials.gov). The company ReNeuron, based in the United Kingdom, is planning a clinical trial in stroke patients involving transplantation of clonal, conditionally immortalized NSCs isolated from human fetal cortex. In the rat stroke model, transplantation of these human cells was shown to ameliorate motor impairments (107), possibly by promoting angiogenesis and improving cerebral blood flow.
Recovery after stroke could potentially also be induced by stimulating endogenous neurogenesis (Figure 4) (see, e.g., refs. 108-110). After stroke in rodents, NSCs and other neuronal progenitors in the SVZ increase their proliferation and generate neuroblasts, which migrate to the damaged area in the striatum during the following months (111-113), are morphologically integrated (114), and seem to become functional mature neurons (115). Stroke-induced neurogenesis is maintained in the aged rat brain (116). There is also evidence in humans for enhanced SVZ cell proliferation and neuroblast formation after stroke (117-119). In mice, ependymal cells lining the lateral ventricle participate in the neurogenic response to stroke by producing new neuroblasts, but their survival is poor (120).

Whether endogenous neurogenesis contributes to spontaneous recovery after stroke has not yet been established. In order to have substantial clinical impact, however, neurogenesis needs to be optimized (Figure 4), and this could be accomplished in several ways. The first way is to increase the survival of the new neuroblasts or mature neurons. Approximately $80 \%$ of neuroblasts and neurons die during the first two weeks after formation (111), and only a fraction survive long-term after stroke in rats. Available data indicate that survival could be improved by administration of inflammation-modulating agents (121-123), caspase inhibitors (113), and/or neurotrophic factors (124). The second way is to promote the migration of the new neurons to the damaged area. Several molecular mechanisms are known to regulate this migration, including those involving stromal cell-derived factor $1 \alpha[$ SDF- $1 \alpha]$; refs. $113,125)$, monocyte chemoattractant protein-1 (126), and matrix metalloproteinase-9 (127). A final way to optimize neurogenesis is to stimulate the differentiation of cortical neurons, which are formed only in limited numbers after stroke (109). Enhancement of cortical neurogenesis has been described in animal models using several approaches, including growth factor delivery $(128,129)$.

As indicated by this discussion, many issues remain before stem cell-based therapy can advance to full-scale clinical trials for the treatment of stroke. For example, it is necessary to determine the type of cells suitable for transplantation; to learn how to control the proliferation, survival, migration, differentiation, and functional integration of endogenous and grafted stem cells and their progeny in the stroke-damaged brain; and to develop procedures for cell delivery, scaling up, optimum functional recovery, and patient selection and assessment (130). Development of cell replacement strategies for stroke is much more challenging than it is for diseases such as PD, and it should be a long-term goal. Stem cell-based treatments that act by neuroprotection, modulation of inflammation, and enhancement of angiogenesis seem closer to application in patients. However, even if some stem cells may be easily accessible for this purpose, for example, autologous bone marrow-derived MSCs, each new approach has to show preclinical evidence of efficacy and safety, and its mechanisms of action in the stroke-damaged brain have to be understood prior to trials in patients.

\section{Stem cell-based therapies for spinal cord injury}

Pathological changes after spinal cord injury are complex and include interruption of ascending and descending pathways, loss of neurons and glial cells, inflammation, scar formation, and demyelination (Figure 5). Patients experience loss of movement, sensation, and autonomic control below the level of the injured spinal segment. Available treatments are ineffective. Different types of stem cells have been implanted in injured spinal cord and improved functional outcome in animal models (see, e.g., refs. 131-133), prob- 


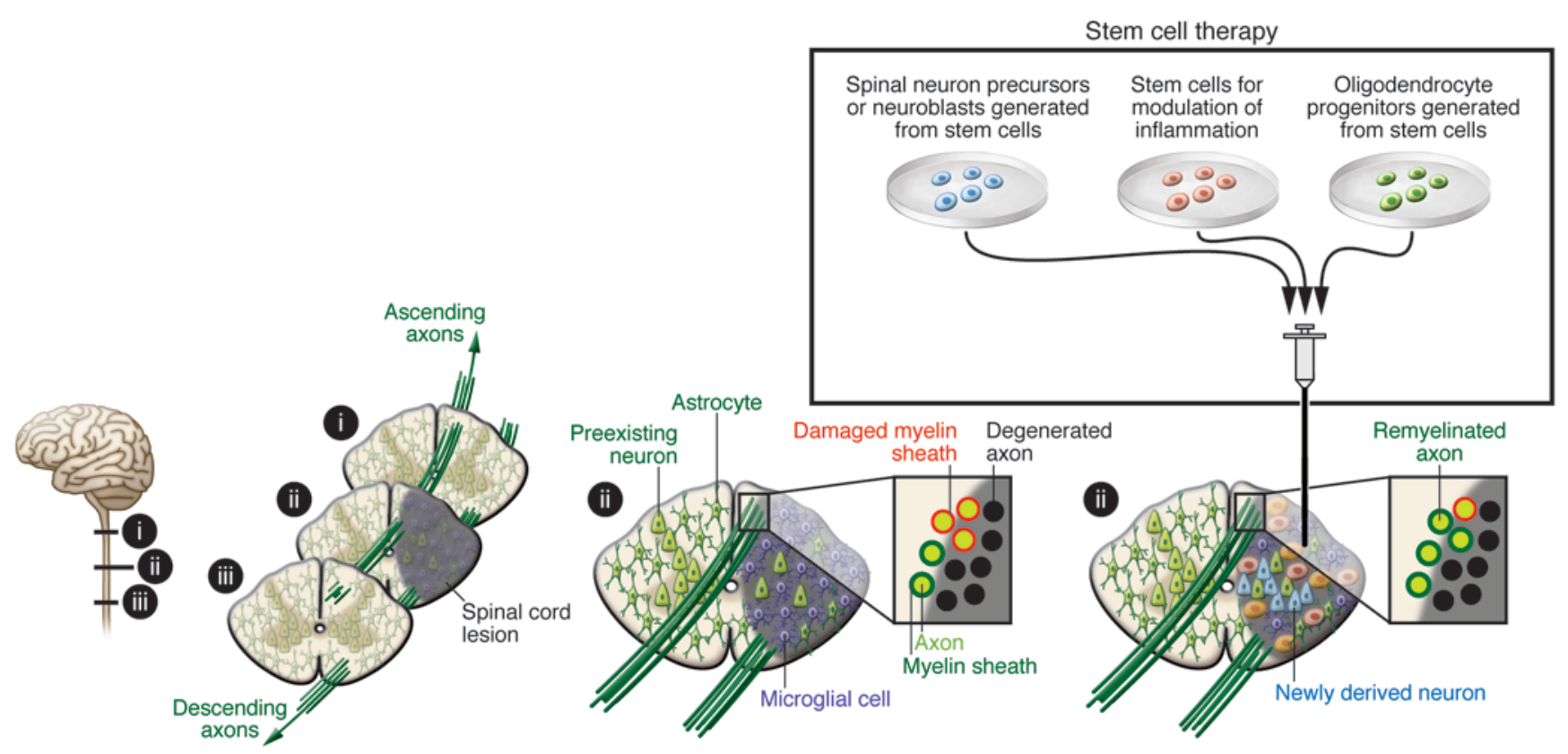

Figure 5

Stem cell-based therapies for spinal cord injury. Spinal cord injury leads to interruption of ascending and descending axonal pathways, loss of neurons and glial cells, inflammation, and demyelination. Stem cell-based therapies could be used to treat individuals with spinal cord injury in several ways. First, transplanting stem cell-derived spinal neuroblasts could lead to the replacement of damaged or dead motor and other neurons. Second, transplanting stem cell-derived OPCs could promote remyelination. Last, transplanting stem cells modified to release different factors could counteract detrimental inflammation.

ably through secretion of neurotrophic factors, remyelination of spared axons, or modulation of inflammation. Recent studies have provided evidence that neurons derived from transplanted human NSCs and other neuronal precursors can become integrated into the spinal cord (Figure 5). For example, human NSCs implanted into injured mouse spinal cord have been found to generate neurons and oligodendrocytes and induce locomotor recovery (134). Integration of neurons derived from the grafted human cells with host circuitry most likely mediated the functional recovery (135). In another study, human NSCs transplanted into the injured rat spinal cord were found to differentiate into neurons that formed axons and synapses and establish contacts with host motor neurons (136). From a clinical perspective, it is important that implanted human NSCs have given rise to mature neurons and oligodendrocytes and promoted functional recovery in injured dogs as well (137).

In addition to transplantation, cell replacement and remyelination after spinal cord injury can also be mediated by endogenous precursors (see, e.g., ref. 138). After spinal cord injury in the mouse, ependymal cells lining the central canal (i.e., the continuation of the brain ventricular system running along the spinal cord) proliferate, migrate toward the damage, and form astrocytes and, to a lesser degree, oligodendrocytes (139). Also, parenchymal progenitors give rise to oligodendrocytes in response to this insult (140). Whether these endogenous regenerative responses can be optimized and harnessed for clinically useful functional benefit is unclear. Recent evidence indicates that human VEGF-secreting NSCs implanted into injured rat spinal cord increase glial progenitor proliferation and oligodendrocyte numbers and promote recovery (141).

Before neuronal replacement strategies can be applied in patients with spinal cord injury (Figure 5), it must be determined how the proliferation of transplanted stem cells and their progeny can be controlled, how the differentiation of these cells to the specific types of neurons that have been lost can be facilitated, and how the resulting neurons can be directed to format appropriate synaptic contacts. Astrocytic differentiation and aberrant axonal sprouting after NSC implantation into the contusion-injured rat thoracic spinal cord has caused forelimb allodynia (142). How such approaches can be scaled up from rodents to humans and adapted to optimize the functional efficacy of NSC transplantation must also be determined prior to application in patients.

Demyelination contributes to loss of function after spinal cord injury (Figure 5), providing a rationale for implanting stem cell-derived cells that remyelinate the remaining axonal pathways to induce symptomatic relief. In support of this approach, improved functional recovery after NSC implantation into injured spinal cord correlated with the number of graft-derived oligodendrocytes and the amount of myelin present (142). High-purity oligodendrocyte progenitor cells (OPCs) generated from human ES cells in vitro have been shown to differentiate into oligodendrocytes and give rise to remyelination after transplantation into the demyelinated mouse spinal cord (143). There seems to be a time window for efficacy, however, because only OPCs implanted in rats early (7 days) but not late (10 months) after spinal cord injury migrated for short distances, differentiated to oligodendrocytes, enhanced remyelination, and improved locomotor function (144). Further, remyelination only occurred after demyelination (145).

Based on these findings, a first phase I clinical trial with human ES cell-derived OPCs is planned by the US company Geron. Patients with thoracic spinal cord injuries will be immunosuppressed for 2 
months after being transplanted with human ES cell-derived OPCs and tested for recovery of sensory and lower extremity motor function. This first trial of human ES cell-derived cells raises concerns about the risk for tumor formation, which is difficult to assess in a preclinical xenograft situation (146), and about the fact that data from rodent models will be directly translated into human patients, as it is not clear how closely the animal models reflect the human condition. Despite these concerns, the risk/benefit ratio of the ES cell-based remyelination approach, for which there is preclinical evidence of efficacy and safety, seems to justify the initiation of clinical trials in spinal cord injury patients who lack effective treatments.

Stem cell-based approaches using umbilical cord blood, bone marrow-derived HSCs, and MSCs have already been applied in patients with spinal cord injury, with claims of partial recovery (131). The problems with the studies in which these approaches were used (147-149) are, in our view, several-fold. First, the implanted cells were often poorly characterized. Second, the preclinical evidence of efficacy for several of these approaches was insufficient. Third, therapeutic benefit was reported from openlabel trials where patients had also been subjected to physiotherapy. Last, the mechanisms underlying observed improvements were unclear. We believe that clinical studies with these cells should not continue until there is a more solid experimental basis and that they should only be conducted with proper controls.

\section{Perspectives}

Stem cell research could lead to the development of radical new therapies for several neurodegenerative diseases that currently lack effective treatments. Over the past few years, there has been continuous progress in developing approaches to generate the types of human-derived neurons and glial cells that are needed for cell replacement therapy based on pathology in the respective diseases $(13,17,40,42,45,88,89,92,93,135-137,143)$. Patient-specific cells that may be useful for transplantation can now be produced from iPS cells $(4,27,32,46,47)$. Also, NSCs in the adult brain generate new neurons and glial cells in response to neurodegeneration (76-81, 109, 110, 139-141). It has become clear that the characteristics of the pathological environment, such as the magnitude of inflammation, play a crucial role in the survival, differentiation, and function of both grafted and endogenous cells (56-58, 77, $81,121-123)$. The mechanisms of action of stem cells and their progeny underlying behavioral recovery in animal models are bet- ter understood than they were just a few years ago. Besides cell replacement, stem cells are known to lead to improvements that could also be of clinical value through immunomodulation, trophic actions, neuroprotection, and stimulation of angiogenesis (5, 60-66, 94-102). So, will these advancements in stem cell research lead to a large number of scientifically justified clinical trials in neurodegenerative diseases within the next couple of years? Transplantation of human ES cell-derived OPCs for remyelination in spinal cord injury is likely to be initiated soon, and stem cell-derived DA neurons are likely to be implanted in PD patients within five years. Clinical attempts at neuronal replacement for stroke, ALS, spinal cord injury, and AD seem more distant. Therapeutic approaches using stem cells mainly for neuroprotection by supplying neurotrophic molecules or modulating inflammation will most likely be applied sooner in these disorders. However, we believe that the clinical harnessing of stem cells to treat neurodegenerative diseases requires more basic research so that the mechanisms regulating the proliferation, migration, differentiation, survival, and function of stem cells and their derivatives are better understood and can be effectively controlled. If stem cell research is to successfully deliver clinically competitive new therapies, it is crucial to have this solid scientific understanding. Some stem cell populations are easily accessible, for example, those in the bone marrow, and less controversial than human ES cells. Clinical application of these cells without preclinical evidence of efficacy and safety, as required for other sources of stem cells, is unacceptable and will delay the development of clinically useful therapies. Most patients with neurodegenerative disorders have few or no therapeutic options and are prepared to test any new approaches. Scientists, clinicians, regulators, and ethicists must act together for the responsible clinical translation of stem cell research into appropriate applications for patients with these disorders.

\section{Acknowledgments}

Our own work was supported by the Swedish Research Council, Juvenile Diabetes Research Foundation, and EU projects LSHB2006-037526 (StemStroke) and 222943 (Neurostemcell).

Address correspondence to: Olle Lindvall, Laboratory of Neurogenesis and Cell Therapy, Wallenberg Neuroscience Center, University Hospital, SE-221 84, Lund, Sweden. Phone: 46-46-222-0543; Fax: 46-46-222-0560; E-mail: olle.lindvall@med.lu.se.
1. Lau D, Ogbogu U, Taylor B, Stafinski T, Menon D, Caulfield T. Stem cell clinics online: the direct-toconsumer portrayal of stem cell medicine. Cell Stem Cell. 2008;3(6):591-594.

2. Kordower JH, Chu Y, Hauser RA, Freeman TB, Olanow CW. Lewy body-like pathology in long-term embryonic nigral transplants in Parkinson's disease. Nat Med. 2008;14(5):504-506.

3. Li JY, et al. Lewy bodies in grafted neurons in subjects with Parkinson's disease suggest host-to-graft disease propagation. Nat Med. 2008;14(5):501-503.

4. Soldner F, et al. Parkinson's disease patient-derived induced pluripotent stem cells free of viral reprogramming factors. Cell. 2009;136(5):964-977.

5. Pluchino $S$, et al. Neurosphere-derived multipotent precursors promote neuroprotection by an immunomodulatory mechanism. Nature. 2005;436(7048):266-271.

6. Lindvall O, Björklund A. Cell therapy in Parkinson's disease. NeuroRx. 2004;1(4):382-393.

7. Piccini $P$, et al. Dopamine release from nigral transplants visualized in vivo in a Parkinson's patient. Nat Neurosci. 1999;2(12):1137-1140.
8. Freed CR, et al. Transplantation of embryonic dopamine neurons for severe Parkinson's disease. N Engl J Med. 2001;344(10):710-719.

9. Olanow $\mathrm{CW}$, et al. A double-blind controlled trial of bilateral fetal nigral transplantation in Parkinson's disease. Ann Neurol. 2003;54(3):403-414.

10. Isacson O, Björklund LM, Schumacher JM. Toward full restoration of synaptic and terminal function of the dopaminergic system in Parkinson's disease by stem cells. Ann Neurol. 2003;53(suppl 3):S135S146; discussion S146-S138.

11. Mendez I, et al. Cell type analysis of functional fetal dopamine cell suspension transplants in the striatum and substantia nigra of patients with Parkinson's disease. Brain. 2005;128(pt 7):1498-1510.

12. Björklund LM, et al. Embryonic stem cells develop into functional dopaminergic neurons after transplantation in a Parkinson rat model. Proc Natl Acad Sci U S A. 2002;99(4):2344-2349.

13. Cho MS, et al. Highly efficient and large-scale generation of functional dopamine neurons from human embryonic stem cells. Proc Natl Acad Sci US A. 2008;105(9):3392-3397.
14. Kawasaki $\mathrm{H}$, et al. Induction of midbrain dopaminergic neurons from ES cells by stromal cell-derived inducing activity. Neuron. 2000;28(1):31-40.

15. Kim JH, et al. Dopamine neurons derived from embryonic stem cells function in an animal model of Parkinson's disease. Nature. 2002;418(6893):50-56.

16. Rodriguez-Gomez JA, et al. Persistent dopamine functions of neurons derived from embryonic stem cells in a rodent model of Parkinson disease. Stem Cells. 2007;25(4):918-928.

17. Roy NS, Cleren C, Singh SK, Yang L, Beal MF, Goldman SA. Functional engraftment of human ES cell-derived dopaminergic neurons enriched by coculture with telomerase-immortalized midbrain astrocytes. Nat Med. 2006;12(11):1259-1268.

18. Sanchez-Pernaute R, et al. Parthenogenetic dopamine neurons from primate embryonic stem cells restore function in experimental Parkinson's disease. Brain. 2008;131(pt 8):2127-2139.

19. Takagi Y, et al. Dopaminergic neurons generated from monkey embryonic stem cells function in a Parkinson primate model. J Clin Invest. 2005;115(1):102-109. 
20. Tabar V, et al. Therapeutic cloning in individual parkinsonian mice. Nat Med. 2008;14(4):379-381.

21. O'Keeffe FE, et al. Induction of A9 dopaminergic neurons from neural stem cells improves motor function in an animal model of Parkinson's disease. Brain. 2008;131(pt 3):630-641.

22. Parish CL, et al. Wnt5a-treated midbrain neural stem cells improve dopamine cell replacement therapy in parkinsonian mice. J Clin Invest. 2008;118(1):149-160.

23. Sanchez-Pernaute R, Studer L, Bankiewicz KS, Major EO, McKay RD. In vitro generation and transplantation of precursor-derived human dopamine neurons. J Neurosci Res. 2001;65(4):284-288.

24. Studer L, Tabar V, McKay RD. Transplantation of expanded mesencephalic precursors leads to recovery in parkinsonian rats. Nat Neurosci. 1998;1(4):290-295.

25. Shim JW, et al. Generation of functional dopamine neurons from neural precursor cells isolated from the subventricular zone and white matter of the adult rat brain using Nurr1 overexpression. Stem Cells. 2007;25(5):1252-1262.

26. Dezawa M, et al. Specific induction of neuronal cells from bone marrow stromal cells and application for autologous transplantation. J Clin Invest. 2004;113(12):1701-1710.

27. Wernig $M$, et al. Neurons derived from reprogrammed fibroblasts functionally integrate into the fetal brain and improve symptoms of rats with Parkinson's disease. Proc Natl Acad Sci US A. 2008;105(15):5856-5861.

28. Andersson E, et al. Identification of intrinsic determinants of midbrain dopamine neurons. Cell. 2006;124(2):393-405

29. Chung $S$, et al. The homeodomain transcription factor Pitx 3 facilitates differentiation of mouse embryonic stem cells into AHD2-expressing dopaminergic neurons. Mol Cell Neurosci. 2005;28(2):241-252.

30. Friling S, et al. Efficient production of mesencephalic dopamine neurons by Lmx1a expression in embryonic stem cells. Proc Natl Acad Sci U S A. 2009;106(18):7613-7618.

31. Hedlund E, et al. Embryonic stem cell-derived Pitx3-enhanced green fluorescent protein midbrain dopamine neurons survive enrichment by fluorescence-activated cell sorting and function in an animal model of Parkinson's disease. Stem Cells. 2008;26(6):1526-1536.

32. Park IH, et al. Disease-specific induced pluripotent stem cells. Cell. 2008;134(5):877-886.

33. Piccini $P$, et al. Factors affecting the clinical outcome after neural transplantation in Parkinson's disease. Brain. 2005;128(pt 12):2977-2986

34. Hagell $\mathrm{P}$, et al. Dyskinesias following neural transplantation in Parkinson's disease. Nat Neurosci. 2002;5(7):627-628.

35. Carlsson T, et al. Impact of grafted serotonin and dopamine neurons on development of L-DOPA-induced dyskinesias in parkinsonian rats is determined by the extent of dopamine neuron degeneration. Brain. 2008;132(pt 2):319-335.

36. Lang AE, Obeso JA. Challenges in Parkinson's disease: restoration of the nigrostriatal dopamine system is not enough. Lancet Neurol. 2004;3(5):309-316.

37. Olanow CW, Kieburtz K, Schapira AH. Why have we failed to achieve neuroprotection in Parkinson's disease? Ann Neurol. 2008;64(suppl 2):S101-S110.

38. Behrstock $S$, et al. Human neural progenitors deliver glial cell line-derived neurotrophic factor to parkinsonian rodents and aged primates. Gene Ther. 2006;13(5):379-388.

39. Roy N, Nakano T, Xuing L, Kang J, Nedergaard M, Goldman SA. Enhancer-specified GFP-based FACS purification of human spinal motor neurons from embryonic stem cells. Exp Neurol. 2005;196(2):224-234.
40. Lee H, et al. Directed differentiation and transplantation of human embryonic stem cell-derived motoneurons. Stem Cells. 2007;25(8):1931-1939.

41. Li XJ, et al. Specification of motoneurons from human embryonic stem cells. Nat Biotechnol. 2005;23(2):215-221.

42. Li XJ, et al. Directed differentiation of ventral spinal progenitors and motor neurons from human embryonic stem cells by small molecules. Stem Cells. 2008;26(4):886-893.

43. Wichterle H, Lieberam I, Porter JA, Jessell TM. Directed differentiation of embryonic stem cells into motor neurons. Cell. 2002;110(3):385-397.

44. Bohl D, Liu S, Blanchard S, Hocquemiller M, Haase G, Heard JM. Directed evolution of motor neurons from genetically engineered neural precursors. Stem Cells. 2008;26(10):2564-2575.

45. Jordan PM, et al. Generation of spinal motor neurons from human fetal brain-derived neural stem cells: role of basic fibroblast growth factor. J Neurosci Res. 2009;87(2):318-332.

46. Dimos JT, et al. Induced pluripotent stem cells generated from patients with ALS can be differentiated into motor neurons. Science. 2008;321(5893):1218-1221.

47. Karumbayaram S, et al. Directed differentiation of human-induced pluripotent stem cells generates active motor neurons. Stem Cells. 2009;27(4):806-811.

48. Harper JM, et al. Axonal growth of embryonic stem cell-derived motoneurons in vitro and in motoneuron-injured adult rats. Proc Natl Acad Sci U S A. 2004;101(18):7123-7128.

49. Miles GB, Yohn DC, Wichterle H, Jessell TM, Rafuse VF, Brownstone RM. Functional properties of motoneurons derived from mouse embryonic stem cells. J Neurosci. 2004;24(36):7848-7858.

50. Deshpande DM, et al. Recovery from paralysis in adult rats using embryonic stem cells. Ann Neurol. 2006;60(1):32-44.

51. Yohn DC, Miles GB, Rafuse VF, Brownstone RM. Transplanted mouse embryonic stem-cellderived motoneurons form functional motor units and reduce muscle atrophy. J Neurosci. 2008;28(47):12409-12418.

52. Soundararajan P, Miles GB, Rubin LL, Brownstone RM, Rafuse VF. Motoneurons derived from embryonic stem cells express transcription factors and develop phenotypes characteristic of medial motor column neurons. J Neurosci. 2006;26(12):3256-3268.

53. Molyneaux BJ, Arlotta P, Hirata T, Hibi M, Macklis JD. Fezl is required for the birth and specification of corticospinal motor neurons. Neuron. 2005;47(6):817-831.

54. Arlotta P, Molyneaux BJ, Chen J, Inoue J, Kominami R, Macklis JD. Neuronal subtype-specific genes that control corticospinal motor neuron development in vivo. Neuron. 2005;45(2):207-221.

55. Ozdinler PH, Macklis JD. IGF-I specifically enhances axon outgrowth of corticospinal motor neurons. Nat Neurosci. 2006;9(11):1371-1381.

56. Di Giorgio FP, Carrasco MA, Siao MC, Maniatis T, Eggan K. Non-cell autonomous effect of glia on motor neurons in an embryonic stem cell-based ALS model. Nat Neurosci. 2007;10(5):608-614.

57. Marchetto MC, Muotri AR, Mu Y, Smith AM, Cezar GG, Gage FH. Non-cell-autonomous effect of human SOD1 G37R astrocytes on motor neurons derived from human embryonic stem cells. Cell Stem Cell. 2008;3(6):649-657.

58. Lepore AC, et al. Focal transplantation-based astrocyte replacement is neuroprotective in a model of motor neuron disease. Nat Neurosci. 2008;11(11):1294-1301.

59. Henkel JS, Beers DR, Zhao W, Appel SH. Microglia in ALS: The good, the bad, and the resting [published online ahead of print September 3, 2009]. J Neuroimmune Pharmacol. doi:10.1007/s11481-009-
9171-5.

60. Kerr DA, et al. Human embryonic germ cell derivatives facilitate motor recovery of rats with diffuse motor neuron injury. J Neurosci. 2003;23(12):5131-5140.

61. Corti S, et al. Neural stem cells LewisX+ CXCR4+ modify disease progression in an amyotrophic lateral sclerosis model. Brain. 2007;130(pt 5):1289-1305.

62. Hwang DH, et al. Intrathecal transplantation of human neural stem cells overexpressing VEGF provide behavioral improvement, disease onset delay and survival extension in transgenic ALS mice. Gene Ther. 2009;16(10):1234-1244.

63. Xu L, et al. Human neural stem cell grafts ameliorate motor neuron disease in SOD-1 transgenic rats. Transplantation. 2006;82(7):865-875

64. Xu L, Ryugo DK, Pongstaporn T, Johe K, Koliatsos VE. Human neural stem cell grafts in the spinal cord of SOD1 transgenic rats: differentiation and structural integration into the segmental motor circuitry. J Comp Neurol. 2009;514(4):297-309.

65 . Klein SM, et al. GDNF delivery using human neural progenitor cells in a rat model of ALS. Hum Gene Ther. 2005;16(4):509-521.

66. Suzuki M, et al. GDNF secreting human neural progenitor cells protect dying motor neurons, but not their projection to muscle, in a rat model of familial ALS. PLoS One. 2007;2(1):e689.

67. Suzuki M, et al. Direct muscle delivery of GDNF with human mesenchymal stem cells improves motor neuron survival and function in a rat model of familial ALS. Mol Ther. 2008;16(12):2002-2010.

68. Appel SH, et al. Hematopoietic stem cell transplantation in patients with sporadic amyotrophic lateral sclerosis. Neurology. 2008;71(17):1326-1334.

69. Mazzini L, et al. Stem cell treatment in amyotrophic lateral sclerosis. J Neurol Sci. 2008;265(1-2):78-83.

70. Vercelli A, et al. Human mesenchymal stem cell transplantation extends survival, improves motor performance and decreases neuroinflammation in mouse model of amyotrophic lateral sclerosis. Neurobiol Dis. 2008;31(3):395-405.

71. Deda H, et al. Treatment of amyotrophic lateral sclerosis patients by autologous bone marrowderived hematopoietic stem cell transplantation: a 1-year follow-up. Cytotherapy. 2009;11(1):18-25

72. Badayan I, Cudkowicz ME. Is it too soon for mesenchymal stem cell trials in people with ALS? Amyotroph Lateral Scler. 2008;9(6):321-322.

73. Manabe T, et al. L3/Lhx8 is a pivotal factor for cholinergic differentiation of murine embryonic stem cells. Cell Death Differ. 2007;14(6):1080-1085.

74. Zhao C, Deng W, Gage FH. Mechanisms and functional implications of adult neurogenesis. Cell. 2008;132(4):645-660.

75. Kempermann G. Adult Neurogenesis: Stem Cells and Neuronal Development in the Adult Brain. 2005. New York, NY: Oxford University Press.

76. Gan L, et al. Neurogenic responses to amyloid-beta plaques in the brain of Alzheimer's disease-like transgenic (pPDGF-APPSw,Ind) mice. Neurobiol Dis. 2008;29(1):71-80

77. Biscaro B, Lindvall O, Hock C, Ekdahl C, and Nitsch R. A $\beta$ immunotherapy protects morphology and survival of adult-born neurons in doubly transgenic APP/PS1 mice. J. Neurosci. 2009;29(45):14108-14119.

78. Jin $\mathrm{K}$, et al. Increased hippocampal neurogenesis in Alzheimer's disease. Proc Natl Acad Sci U S A. 2004;101(1):343-347.

79. Boekhoorn K, Joels M, Lucassen PJ. Increased proliferation reflects glial and vascular-associated changes, but not neurogenesis in the presenile Alzheimer hippocampus. Neurobiol Dis. 2006;24(1):1-14.

80. Li B, et al. Failure of neuronal maturation in Alzheimer disease dentate gyrus. J Neuropathol Exp Neurol. 2008;67(1):78-84.

81. Becker M, Lavie V, Solomon B. Stimulation 
of endogenous neurogenesis by anti-EFRH immunization in a transgenic mouse model of Alzheimer's disease. Proc Natl Acad Sci U S A. 2007;104(5):1691-1696.

82. Tuszynski MH, et al. A phase 1 clinical trial of nerve growth factor gene therapy for Alzheimer disease. Nat Med. 2005;11(5):551-555.

83. Nagahara AH, et al. Neuroprotective effects of brain-derived neurotrophic factor in rodent and primate models of Alzheimer's disease. Nat Med. 2009; 15(3):331-337.

84. Hemming ML, Patterson M, Reske-Nielsen C, Lin $\mathrm{L}$, Isacson O, Selkoe DJ. Reducing amyloid plaque burden via ex vivo gene delivery of an Abetadegrading protease: a novel therapeutic approach to Alzheimer disease. PLoS Med. 2007;4(8):e262.

85 . Meilandt WJ, et al. Neprilysin overexpression inhibits plaque formation but fails to reduce pathogenic Abeta oligomers and associated cognitive deficits in human amyloid precursor protein transgenic mice. J Neurosci. 2009;29(7):1977-1986.

86. Bacigaluppi M, Pluchino S, Martino G, Kilic E, Hermann DM. Neural stem/precursor cells for the treatment of ischemic stroke. J Neurol Sci. 2008;265(1-2):73-77.

87. Locatelli F, et al. Stem cell therapy in stroke. Cell Mol Life Sci. 2009;66(5):757-772.

88. Daadi MM, Maag AL, Steinberg GK. Adherent selfrenewable human embryonic stem cell-derived neural stem cell line: functional engraftment in experimental stroke model. PLoS One. 2008;3(2):e1644.

89. Daadi MM, et al. Molecular and magnetic resonance imaging of human embryonic stem cell derived neural stem cell grafts in ischemic rat brain Mol Ther. 2009;17(7):1282-1291.

90. Buhnemann C, et al. Neuronal differentiation of transplanted embryonic stem cell-derived precursors in stroke lesions of adult rats. Brain. 2006;129(pt 12):3238-3248

91. Kelly S, et al. Transplanted human fetal neural stem cells survive, migrate, and differentiate in ischemic rat cerebral cortex. Proc Natl Acad Sci US A. 2004;101(32):11839-11844

92. Kallur T, Darsalia V, Lindvall O, Kokaia Z. Human fetal cortical and striatal neural stem cells generate region-specific neurons in vitro and differentiate extensively to neurons after intrastriatal transplantation in neonatal rats. $J$ Neurosci Res. 2006;84(8):1630-1644.

93. Darsalia V, Kallur T, Kokaia Z. Survival, migration and neuronal differentiation of human fetal striatal and cortical neural stem cells grafted in stroke-damaged rat striatum. Eur J Neurosci. 2007;26(3):605-614.

94. Lee ST, et al. Anti-inflammatory mechanism of intravascular neural stem cell transplantation in haemorrhagic stroke. Brain. 2008;131(pt 3):616-629.

95. Lee HJ, Kim KS, Park IH, Kim SU. Human neural stem cells over-expressing VEGF provide neuroprotection, angiogenesis and functional recovery in mouse stroke model. PLoS One. 2007;2(1):e156.

96. Lee HJ, Kim MK, Kim HJ, Kim SU. Human neural stem cells genetically modified to overexpress akt1 provide neuroprotection and functional improvement in mouse stroke model. PLoS One. 2009;4(5):e5586.

97. Onda T, Honmou O, Harada K, Houkin K, Hamada H, Kocsis JD. Therapeutic benefits by human mesenchymal stem cells (hMSCs) and Ang- 1 genemodified hMSCs after cerebral ischemia. J Cereb Blood Flow Metab. 2008;28(2):329-340.

98. Horita Y, Honmou O, Harada K, Houkin K, Hamada H, Kocsis JD. Intravenous administration of glial cell line-derived neurotrophic factor genemodified human mesenchymal stem cells protects against injury in a cerebral ischemia model in the adult rat. J Neurosci Res. 2006;84(7):1495-1504.

99. Liu H, et al. Neuroprotection by PlGF gene-modi- fied human mesenchymal stem cells after cerebral ischaemia. Brain. 2006;129(pt 10):2734-2745.

100.Nomura T, Honmou O, Harada K, Houkin K, Hamada H, Kocsis JD. I.V. infusion of brainderived neurotrophic factor gene-modified human mesenchymal stem cells protects against injury in a cerebral ischemia model in adult rat. Neuroscience. 2005;136(1):161-169.

101.Liu YP, Seckin H, Izci Y, Du ZW, Yan YP, Baskaya MK. Neuroprotective effects of mesenchymal stem cells derived from human embryonic stem cells in transient focal cerebral ischemia in rats. J Cereb Blood Flow Metab. 2009;29(4):780-791.

102. Bacigaluppi M, et al. Delayed post-ischaemic neuroprotection following systemic neural stem cell transplantation involves multiple mechanisms. Brain. 2009;132(pt 8):2239-2251.

103.Kondziolka D, et al. Neurotransplantation for patients with subcortical motor stroke: a phase 2 randomized trial. J Neurosurg. 2005;103(1):38-45.

104. Kondziolka D, et al. Transplantation of cultured human neuronal cells for patients with stroke. New rology. 2000;55(4):565-569.

105.Nelson PT, et al. Clonal human (hNT) neuron grafts for stroke therapy: neuropathology in a patient 27 months after implantation. Am J Pathol. 2002;160(4):1201-1206.

106.Bang OY, Lee JS, Lee PH, Lee G. Autologous mesenchymal stem cell transplantation in stroke patients. Ann Neurol. 2005;57(6):874-882.

107. Pollock K, et al. A conditionally immortal clonal stem cell line from human cortical neuroepithelium for the treatment of ischemic stroke. Exp Neurol. 2006;199(1):143-155.

108.Greenberg DA, Jin K. Regenerating the brain. Int Rev Neurobiol. 2007;77:1-29.

109.Lindvall O, Kokaia Z. Neurogenesis following stroke affecting the adult brain. In: Gage F, Kempermann G, Song H, eds. Adult neurogenesis. Cold Spring Harbor, NY: Cold Spring Harbor Laboratory Press; 2008:549-570.

110.Zhang ZG, Chopp M. Neurorestorative therapies for stroke: underlying mechanisms and translation to the clinic. Lancet Neurol. 2009;8(5):491-500.

111.Arvidsson A, Collin T, Kirik D, Kokaia Z, Lindvall O. Neuronal replacement from endogenous precursors in the adult brain after stroke. Nat Med. 2002;8(9):963-970

112.Parent JM, Vexler ZS, Gong C, Derugin N, Ferriero DM. Rat forebrain neurogenesis and striatal neuron replacement after focal stroke. Ann Neurol. 2002;52(6):802-813.

113. Thored $\mathrm{P}$, et al. Persistent production of neurons from adult brain stem cells during recovery after stroke. Stem Cells. 2006;24(3):739-747.

114. Yamashita T, et al. Subventricular zone-derived neuroblasts migrate and differentiate into mature neurons in the post-stroke adult striatum. J Neurosci. 2006;26(24):6627-6636.

115. Hou SW, et al. Functional integration of newly generated neurons into striatum after cerebral ischemia in the adult rat brain. Stroke. 2008;39(10):2837-2844.

116. Darsalia V, Heldmann U, Lindvall O, Kokaia Z Stroke-induced neurogenesis in aged brain. Stroke. 2005;36(8):1790-1795.

117. Jin $\mathrm{K}$, et al. Evidence for stroke-induced neurogenesis in the human brain. Proc Natl Acad Sci US A. 2006;103(35):13198-13202.

118. Macas J, Nern C, Plate KH, Momma S. Increased generation of neuronal progenitors after ischemic injury in the aged adult human forebrain. J Neurosci. 2006;26(50):13114-13119.

119. Minger SL, Ekonomou A, Carta EM, Chinoy A, Perry RH, Ballard CG. Endogenous neurogenesis in the human brain following cerebral infarction. Regen Med. 2007;2(1):69-74.

120. Carlen M, et al. Forebrain ependymal cells are Notchdependent and generate neuroblasts and astrocytes after stroke. Nat Neurosci. 2009;12(3):259-267.

121. Hoehn BD, Palmer TD, Steinberg GK. Neurogenesis in rats after focal cerebral ischemia is enhanced by indomethacin. Stroke. 2005;36(12):2718-2724.

122. Liu Z, et al. Chronic treatment with minocycline preserves adult new neurons and reduces functional impairment after focal cerebral ischemia. Stroke. 2007;38(1):146-152.

123. Thored $\mathrm{P}$, et al. Long-term accumulation of microglia with proneurogenic phenotype concomitant with persistent neurogenesis in adult subventricular zone after stroke. Glia. 2009;57(8):835-849.

124.Kobayashi T, Ahlenius H, Thored P, Kobayashi R, Kokaia Z, Lindvall O. Intracerebral infusion of glial cell line-derived neurotrophic factor promotes striatal neurogenesis after stroke in adult rats. Stroke. 2006;37(9):2361-2367.

125. Robin AM, et al. Stromal cell-derived factor 1alpha mediates neural progenitor cell motility after focal cerebral ischemia. J Cereb Blood Flow Metab. 2005;26(1):125-134.

126.Yan YP, Sailor KA, Lang BT, Park SW, Vemuganti R, Dempsey RJ. Monocyte chemoattractant protein-1 plays a critical role in neuroblast migration after focal cerebral ischemia. J Cereb Blood Flow Metab. 2006;27(6):1213-1224.

127. Lee SR, et al. Involvement of matrix metalloproteinase in neuroblast cell migration from the subventricular zone after stroke. J Neurosci. 2006;26(13):3491-3495

128. Kolb B, et al. Growth factor-stimulated generation of new cortical tissue and functional recovery after stroke damage to the motor cortex of rats. J Cereb Blood Flow Metab. 2006;27(5):983-997.

129. Wang YQ, et al. VEGF enhance cortical newborn neurons and their neurite development in adult rat brain after cerebral ischemia. Neurochem Int 2009;55(7):629-636.

130.The STEPS Participants. Stem Cell Therapies as an Emerging Paradigm in Stroke (STEPS): bridging basic and clinical science for cellular and neurogenic factor therapy in treating stroke. Stroke. 2009;40(2):510-515.

131.Jain KK. Cell therapy for CNS trauma. Mol Biotechnol. 2009;42(3):367-376.

132.Kim SU, de Vellis J. Stem cell-based cell therapy in neurological diseases: a review. J Neurosci Res. 2009;87(10):2183-2200

133.Louro J, Pearse DD. Stem and progenitor cell therapies: recent progress for spinal cord injury repair. Neurol Res. 2008;30(1):5-16.

134.Cummings BJ, et al. Human neural stem cells differentiate and promote locomotor recovery in spinal cord-injured mice. Proc Natl Acad Sci US A. 2005;102(39):14069-14074.

135.Hooshmand MJ, Sontag CJ, Uchida N, Tamaki $\mathrm{S}$, Anderson AJ, Cummings BJ. Analysis of hostmediated repair mechanisms after human CNSstem cell transplantation for spinal cord injury: correlation of engraftment with recovery. PLoS One. 2009;4(6):e5871.

136.Yan J, et al. Extensive neuronal differentiation of human neural stem cell grafts in adult rat spinal cord. PLoS Med. 2007;4(2):e39.

137. Lee SH, et al. 2009. Effects of human neural stem cell transplantation in canine spinal cord hemisection. Neurol Res. 2009;31(9):996-1002.

138.Barnabe-Heider F, Frisen J. Stem cells for spinal cord repair. Cell Stem Cell. 2008;3(1):16-24.

139. Meletis K, et al. Spinal cord injury reveals multilineage differentiation of ependymal cells. PLoS Biol. 2008;6(7):e182.

140.Ohori Y, et al. Growth factor treatment and genetic manipulation stimulate neurogenesis and oligodendrogenesis by endogenous neural progenitors in the injured adult spinal cord. J Neurosci. 2006;26(46):11948-11960.

141. Kim HM, Hwang DH, Lee JE, Kim SU, Kim BG. Ex 
vivo VEGF delivery by neural stem cells enhances proliferation of glial progenitors, angiogenesis, and tissue sparing after spinal cord injury. PLoS One. 2009;4(3):e4987.

142. Hofstetter CP, et al. Allodynia limits the usefulness of intraspinal neural stem cell grafts; directed differentiation improves outcome. Nat Neurosci. 2005;8(3):346-353.

143. Nistor GI, Totoiu MO, Haque N, Carpenter MK, Keirstead HS. Human embryonic stem cells differentiate into oligodendrocytes in high purity and myelinate after spinal cord transplantation. Glia. 2005;49(3):385-396.
144. Keirstead HS, et al. Human embryonic stem cellderived oligodendrocyte progenitor cell transplants remyelinate and restore locomotion after spinal cord injury. J Neurosci. 2005;25(19):4694-4705.

145.Cloutier F, Siegenthaler MM, Nistor G, Keirstead HS. Transplantation of human embryonic stem cell-derived oligodendrocyte progenitors into rat spinal cord injuries does not cause harm. Regen Med. 2006;1(4):469-479.

146.Erdo F, et al. Host-dependent tumorigenesis of embryonic stem cell transplantation in experimental stroke. J Cereb Blood Flow Metab. 2003;23(7):780-785.
147. Cristante AF, et al. Stem cells in the treatment of chronic spinal cord injury: evaluation of somatosensitive evoked potentials in 39 patients. Spinal Cord. 2009;47(10):733-738.

148. Moviglia GA, et al. Case report on the clinical results of a combined cellular therapy for chronic spinal cord injured patients. Spinal Cord. 2009;47(6):499-503.

149.Park HC, et al. Treatment of complete spinal cord injury patients by autologous bone marrow cell transplantation and administration of granulocyte-macrophage colony stimulating factor. Tissue Eng. 2005;11(5-6):913-922. 